\title{
FOLLOW THE LEADER? TESTING FOR THE INTERNALIZATION OF LAW ${ }^{1}$
}

\author{
Shaun Larcom, ${ }^{\mathrm{a}}$ Luca A. Panzone, ${ }^{\mathrm{b}}$ Timothy Swanson ${ }^{\mathrm{c}}$ \\ ${ }^{\mathrm{a}}$ University of Cambridge; \\ ${ }^{\mathrm{b}}$ Newcastle University; \\ ${ }^{c}$ Graduate Institute Geneva (IHEID). Corresponding Author.
}

\begin{abstract}
The internalization of law is said to be a process that involves a change in people's intrinsic motivation to act in accord with law's obligations - so that it is possible to observe imposed obligations become individual choices. We empirically test for this phenomenon, by attempting to disentangle the impacts of a legal change (a 5 pence charge on use of plastic bags) on intrinsic motivation and individual choice. We do so by measuring both behaviors and attitudes before and after the legal change, and by comparing the impacts across neighboring jurisdictions without the change. Using a differences-in-differences (DID) estimator we find evidence for the internalization of law: that is, we find a significant increase in intrinsic motivation for those consumers subject to the implementation of the legislative change, and link this change in intrinsic motivation to an actual change in behavior. However, using mediation analysis we find that internalization of the law only explains around 5 to $8 \%$ of the change in behavior - the rest being attributable to the direct effect of the charge.
\end{abstract}

Keywords: internalization of law; behavioral; mediation analysis.

JEL codes: Q5; D1; K1; C4.

\footnotetext{
${ }^{1} \mathrm{We}$ are grateful for funding from our respective departments and institutions. We are also appreciative of comments from participants at the European Association of Environmental and Resource Economics Conference, Zurich 2016, the European Law and Economics Association Conference, Bologna 2016, the Society for Environmental Law and Economics, Oxford 2017, and to the Editor and one anonymous referee for very helpful comments on an earlier version of this paper.
} 


\section{Introduction}

How much of real-world behavior is driven by internalized principles of law, and how much of it is motivated by the economic incentives implicit in law's sanctions? For example, do drivers stay stationary at red lights in the middle of the night because it is an internalized obligation to do so, or because of the fear of the sanction that might result if they do not? That is, is this a principle being observed, a price being avoided, or some combination of the two? There is likely to be some of each occurring at every red light in every society; we wish to know if it is possible to separate out between these functions of law.

A survey of experimental literature related to this issue provides two real-world examples that illustrate the potentially divergent impacts of sanctions as economic incentives. Bowles and PolaniaReyes (2012) cite the classic example of the Haifa school that introduced a fine against late pick-ups, inducing a rash of lateness. And they contrast this with the example of the Irish plastic bag charge, in which the introduction of a 15 cent charge on each bag resulted in an almost immediate and absolute reduction of $94 \%$ in the regulated activity (Convery et. al. 2007). They argue that these examples, and many experimental results, demonstrate that incentives do not always operate in the manner of a system of prices applied to non-conforming behavior. A change in law (or other policy) can induce responses that are more in line with a theory of internalized compliance than the theory of deterrence via monitoring and sanction. ${ }^{2}$ It is possible that both are present to some extent in regard to any given change in law.

\footnotetext{
${ }^{2}$ There is a substantial literature demonstrating that this more complex response may sometimes be observed by consequence of its occasional negation. The classic example is the changed policy in Haifa of school-imposed late fees imposed on parents for the late collection of children (Gneezy and Rustichini, 2010). In this example the parents responded to the late fee by increasing the rate at which they were tardy, using the sanction as the price of additional childcare rather than as a sanction or guide to anti-social behaviour. Similarly, new policymaking by the Boston Fire Department backfired when they introduced a fixed schedule of "sick leave days", and fines for excessive leave. The response to the fines was an increase of more than $100 \%$ in the number of days claimed, especially around holiday times (Belkin, 2002; Greenberger 2003). Fines for staying-on in hospital beds in Norway had the same effect (Holmas et. al. 2010). This tradition of potentially perverse responses to economic incentives harkens back to the example of payment for blood donations first cited by Titmuss (1971), and demonstrates that norms and principles (without express sanctions) can indeed have an own-effect, which can be negated by the introduction of penalties.
} 
This paper aims to undertake an empirical assessment of the direct (price-based) effect and the more indirect (internalized motivational) effect. We wish to both estimate the impact of the legal change, and to separate out between its direct and indirect impacts.

In order to perform these various estimations, we study the impact of the recent adoption of a law in England that mandated a charge for the use of new plastic bags. To ascertain the impact of the law, we use the existence of differences in law in neighboring jurisdictions to perform differences-indifferences estimation. In order to separate out between the impact of the new charge in terms of direct and indirect (i.e. internalized) impacts, we undertake a staged survey of UK residents commencing immediately before, and continuing for several months after, the implementation of the new law. ${ }^{3}$ In this way we assess the relationship between stated differences in changed behavior and changed motivation, and compare this to the overall response. We then undertake a mediation analysis, attributing that part of the changed behavior that does not appear to be related to selfreported changes in internalized motivation to the impact of the economic incentive. Our findings are that consumers responded to the change in English law, with changes in behavior that appear to derive in part from the reported changes in internalized motivation. This reported change in personal motivation accounts for about 5 to 8 percent of the change in behavior in our study. In this sense, this change in law has had some measurable "own-effect": there exists a discernible and significant effect of law purely associated to the reported change in intrinsic motivations.

We proceed as follows. In section 2 we briefly review the literature on the impacts of legal intervention via changed internal motivation. In section 3 we set out our strategy for analyzing this policy experiment and describe the policy intervention and the survey conducted around it. In section 4 we set out the basic results from the survey and our analysis of what it implies for the existence of the internalization of law. In section 5 we provide a brief discussion of our results, and how they provide evidence for the internalization of law. In section 6 we conclude.

\footnotetext{
${ }^{3}$ The English law included a price-based sanction of 5 pence for the continuing use of new plastic bags, and so it is necessary to acquire additional information from consumers to assess the extent to which they responded to the principle or the price.
} 


\section{Literature: The Internalization of Law}

The classic literature on the nature of the response to legal change has long suggested that the introduction of a new principle or policy can generate responses consisting of both direct and indirect effects. ${ }^{4} \quad$ Legal scholars such as Cooter (1998), McAdams (1997), and Sunstein (1996) have highlighted the expressive function of law. In this conception the law-maker expresses a statement about appropriate behavior that can then lead to a change in prevailing preferences, beliefs, and norms. ${ }^{5}$ As noted by Scott (2000), such statements can influence individual behavior via various channels, including the internalization of the legal rule by individual citizens (generating selfenforcement of stated principles). In this respect, Etzioni $(2000,167)$ observes that internalization may be viewed as "a remarkable process through which imposed obligations (compliance with which must be forced or paid for) become desires."

There are also other approaches to understanding internalization. Kaplow and Shavell (2007) propose a specific model of internalized behavioral change in response to the statement of a new legal principle. In their model, they hypothesize the existence of an in-built system of individual preferences for acting in conformity with the law. The authors assume that both the characteristic of guilt (giving rise to a negative impact on individual utility by reason of actions in conflict with law) and of virtue (giving rise to a positive impact on individual utility from actions in conformity with law) may exist within an individual's objective function, motivating individual behavior in the direction of newly stated legal principles. Further, these components of utility may be given greater effect by means of the law-maker's expenditures on "inculcation". In this view, individual objectives become an amalgam of both the direct utility received from specific acts in given situations (deriving from the benefits and costs flowing from those choices in that legal environment), and the indirect utility received simply from acting in conformity with stated legal principles.

\footnotetext{
${ }^{4}$ Hart $(1997,242)$ famously suggested the mechanism of the internal point of view, which is manifested by 'accepting the law as providing guides to their conduct and standards or criticism'. Once this viewpoint is adopted, one moves from 'observer' to a 'member', and the member uses the law as a guide for his or her conduct and in determining what is good (or right) behavior.

${ }^{5}$ This mechanism is often associated with ameliorating collective action problems (see Sunstein 1996).
} 
These are the sort of phenomena that we will be attempting to measure here. As seen above, there are various theories for explaining various channels for how such internalization might occur, e.g. via changed preferences (Cooter 1998, Etzioni 2000); utility from self-perception or self-image (Besley and Ghatak 2009) ${ }^{6}$; utility from conformity (Kaplow and Shavell 2007); utility from custom or convention (Lin and Yang 2006) ${ }^{7}$. Any of these approaches might provide the channel for internalization, and self-reported intrinsic motivation would occur. We focus on measuring intrinsic motivation (irrespective of channel) and consequent internalization. That is, here we are exploring the specific question of the measurement of the existence of motivational change occurring as a consequence of legal change, and its link to behavior.

There are many examples of experimental studies examining and measuring the impact of stated principles (norms, mores, laws) on internal motivation. There are also numerous case studies demonstrating specific impacts of stated policies within particular types of organizations (governmental departments, public services). To our knowledge, there is little evidence of the impact of specific expressions of legal change on individual motivation and behavior. ${ }^{8}$

As mentioned, there are numerous experimental studies examining the general question of the manner in which principled statements impact upon motivational change. (See e.g. Galbiati and Vertova, 2014; Tyran and Feld, 2006; Dal Bo and Dal Bo, 2014; Romaniuc et al 2016, Romaniuc 2016) Galbiati and Vertova (2014) investigate the notion of "obligations" as norms, in which the subjects are informed of the contribution required to achieve the cooperative outcome. They find that in this case behavior consistent with such norms can be sustained as observed outcomes, even when

\footnotetext{
${ }^{6}$ For example, there is also a literature exploring the manner in which individuals might be motivated in the more particular context of case studies of specific organizational policies, e.g. policies used to encourage professionalism in the operation of a public hospital or governmental department. (Besley, Bevan and Burchardt 2009; Kreps, 1997; Besley and Ghatak, 2016) In these studies it has been argued that self-perceived reputational effects might afford an important conduit through which individual utility is received and, when this is the case, individual non-compliance with a stated norm might impact upon an individual's own self-image and so detract from individual utility. Such might be the basis for the effectiveness of such policies as "naming and shaming". (Besley and Ghatak 2016)

${ }^{7}$ These authors argue that individuals might secure utility from acting in conformity with a custom or convention, and that law might be one means of enunciating an existing or desirable custom.

${ }^{8}$ The one exception might be the abolition of Swiss voting laws. There it was found that the withdrawal of the legal requirement for voting significantly reduced voter turn-out, even though the penalties under the law were nominal, evidence that it was the language of the law that was operative. (Funk 2007)
} 
inconsistent with the individual optimum. Similarly, Tyran and Feld (2006) find that subjects will respond positively to principles adopted by the group, in that this encourages the expectation that other individuals will do likewise. The Dal Bo and Dal Bo (2014) study pursues this idea, and observes the extent to which players cooperate in situations when some subjects are exposed to stated principles or norms (e.g. the "Golden Rule"), and other subjects are not. They find that such general statements of principles may indeed be effective in motivating those individuals to behave more cooperatively, even in cases when the respondents know that the other players are not so informed. ${ }^{9}$ These and other experiments provide substantial evidence that, in laboratory settings, there can be an impact of expressed principles on individual motivation, through various potential channels. ${ }^{10}$

In terms of empirical work related specifically to the internalization of law, there is a substantial related literature that analyzes how the size of penalties impacts upon the response to social norms. ${ }^{11}$ Much of this work is also experimental. ${ }^{12}$ There are also studies examining how the provision of information regarding penalties impacts upon conformity with law (libraries, television licenses). ${ }^{13}$ We do not analyze the issue of varying penalties further here, since our example includes only the single change in penalty amount. ${ }^{14}$

In sum, the literature on the capacity for stated principles to alter individual motivation has crossed many fields of study and has been discussed in many different contexts. There is much

\footnotetext{
${ }^{9}$ The absence of other players' exposure to the stated principle in some of the treatments is important because it translates the motivational question into one that is individual rather than reciprocal. The exposed individual is then assumed to be responding to altered internal motivations, rather than a changed perception on the likelihood of the other players' responses.

${ }^{10}$ By way of contrast, other laboratory-based studies provide results that bring into question the impact of such expressions of law. (Romaniuc 2016; Romaniuc et al 2016)

${ }^{11}$ The studies on penalties for tax compliance and evasion are voluminous. (Kleven et. al. 2011; Fellner et. al. 2013; Dwenger et. al. 2015) These studies sometimes find that evasion of the legal duty can increase with the sanction. (Berger et. al 2016)

${ }^{12}$ Khadjavi (2014) has investigated whether pro-social behaviour is crowded out in with introduction of penalties in an experimental setting. (see in general Bowles and Polania-Reyes 2012)

${ }^{13} \mathrm{~A}$ recent field experiment with library late fees found that notices that incorporated information on penalties increased compliance. (Apesteguia et. al. 2013) A similar result was found with regard to TV licensepayments. (Fellner et. al. 2013). We provide some speculations on the manner in which the size of penalties might convey some information on the nature of the duty being conferred. See the discussion of results in Section 5.

${ }^{14}$ Another set of related work focuses more on the question of how the stated quantum of the penalty or sanction may alter individual motivations. (see Benabou and Tirole 2011a; Benabou and Tirole 2006) It is based on the idea of individual morality and reputation developed by the same authors. (Benabou and Tirole 2011b) In this framework the individual receives direct utility from conforming with the expressed legal principle but this amount varies across individuals, and the penalty's amount calls forth different levels of individual effort, as an altered wage might alter the amount of effort supplied within an organization.
} 
agreement that some manner of impact on individual choice may be observed from the mere statement of principle, but little attempt has been made to make a precise and structured estimate of the phenomenon in the context of a specific legal change. In terms of measuring the internalization of the law, and separating out between its priced-based and motivational effects on individual behavior, the empirical literature is for the most part silent. In the next section we set out how we propose to accomplish this task.

\section{Measuring Internalization of Legal Change: Context and Method}

The legal context we investigate concerns the introduction of a mandatory plastic bag charge throughout England in 2015. ${ }^{15}$ Similar to what occurred in Ireland ten years earlier, the mandatory charge of 5 pence on plastic bags was implemented across England on 5 October 2015. ${ }^{16}$ Prior to this intervention, the regulation of this commodity in England was undertaken solely on a voluntary basis. ${ }^{17}$ The plastic bag charge went into effect for the expressed purpose of "eliminating the unnecessary use of this item.”

The government took an active role in publicizing the reasoning behind the proposed charge. ${ }^{18}$ It made the case for the reduction of plastic bags being considered as an individual responsibility. The

\footnotetext{
${ }^{15}$ The Single Use Carrier Bags Charge (England) Order (2015). The operative provision of this order provided as follows "A seller must charge a minimum of 5 pence (including any VAT) for each single use carrier bag supplied in the reporting year..." (Article 3). Interestingly, the amount of the charge was the same in each of the neighboring jurisdictions adopting it (England, Wales, Scotland), which may be important for explaining the phenomenon of convergence that will be discussed in Section 5, below.

${ }^{16}$ From this date supermarkets and other large retailers in England were required by law to charge at least 5 pence for single-use plastic carrier bags. The legislative change followed the introduction of mandatory charges being introduced in Wales in October 2011, Northern Ireland in April 2013, and Scotland in October 2014.

${ }^{17}$ Prior to the introduction of the mandatory charge, the government used voluntary schemes to try to reduce the use of plastic bags. In 2008 the British Retail Consortium signed a voluntary agreement which saw the distribution of plastic bags almost halve in 2009 compared to their peak in 2006 of 12.1 billion (House of Commons, 2014, WRAP, 2015). With the exception of one retailer (Marks \& Spencer), who introduced a voluntary charge on plastic bags (discussed below), retailers agreed to reduce uptake of new plastic bags by making them less accessible to consumers. However, despite an initial reduction, plastic bag consumption resumed, increasing by approximately 4 per cent per annum to 8.5 billion in 2014 (WRAP, 2015). In explaining its decision to introduce the charge, the UK Government (2015) cited the fact that the use of plastic carrier bags had increased five years in a row.

${ }^{18}$ The charge was announced in September 2013; the then Deputy Prime Minister announced plans to introduce a mandatory five pence charge for single-use plastic carrier bags in England from Autumn 2015. Following the announcement a Call for Evidence was publicized. As key aspects of the charge were already announced (most importantly the magnitude of the charge) the consultation focused on types of bags to be included and compliance issues. 185 responses were received from industry groups; NGOs; local authorities; academics; and
} 
government stated that single use plastic carrier bags "take longer than other bags to degrade in the environment, can damage wildlife, and are extremely visible when littered in our towns, parks and the countryside." (UK Government, 2015) The government also publicized the social benefits from minimizing plastic bag usage - $£ 6$ million per year in savings from litter clean-up costs and $£ 1.3$ million per year in carbon savings. ${ }^{19}$ In undertaking this pre-implementation phase of publicity, the government was making the policy widely-known as a social responsibility and encouraging public acceptance. $^{20}$

In order to measure the impact of this legal change on individuals in England, and to separate out between its direct and indirect components, we proceed as follows. First, we define the internalization of law as a process that involves a change in the individual's intrinsic motivation to choose action in conformity with the statement of law. ${ }^{21}$ So, in our context (of a new law penalizing the use of new plastic bags), we consider that internalization occurs if the change in law increases an individual's self-reported intrinsic motivation toward using fewer new bags.

Three successive cross-sectional surveys of the UK population were undertaken in order to procure the required information on attitudes and consumption. ${ }^{22}$ The required charge for plastic bags came into force in England on October $5^{\text {th }}, 2015$. To assess consumption and attitudes just before the introduction of the charge, the first survey took place on the $29^{\text {th }}-30^{\text {th }}$ of September $2015 .^{23}$ A second survey collected data one week after the introduction of the policy, on the $13^{\text {th }}-14^{\text {th }}$ of October 2015 .

private individuals (2000 emails were also received). The majority of the respondents supported the introduction of a charge on plastic bags. The House of Commons Audit Committee also produced a report into the proposal and made a public call for witnesses.

${ }^{19}$ In addition retailers are required to donate the funds raised to 'good causes', resulting in projected receipts of $£ 73$ million per annum for charity.

${ }^{20}$ These are two of the conditions that Bowles and Polania-Reyes (2012) argue are necessary to create this effect, publicity and public observation of non-compliants. Public acceptance of a law was shown to be important to self-implemention in Feld and Tyran (2006).

${ }^{21}$ The operational statement here is that the intrinsic motivation of the individual is altered by the statement of law, irrespective of the precise channel through which this change in motivation occurs.

${ }^{22}$ We do not know of any comparable pre-trend data, and so our analysis focuses only on the data generated in our surveys, which comprised of a single wave prior to the legislative change. However, it is instructive to note that the UK's Waste and Resources Action Program (WRAP) collects aggregate data at the country level at yearly intervals. This data shows that, prior to the plastic bag charge being introduced in England, bag usage was trending upwards in all three jurisdictions (England, Wales, Scotland). Their data also demonstrates a sharp decline in bag usage in each jurisdiction following introduction of the charge. (see www.wrap.org.uk)

${ }^{23}$ It should be noted that the introduction of charge was known in advance, so it is possible that some internalization could have occurred prior to the charge actually coming into force. Therefore, the results capture the effect of the charge actually being implemented. 
A final round was implemented seven weeks after the introduction of the carrier bag charge $\left(24^{\text {th }}-25^{\text {th }}\right.$ November, 2015) to capture the longer-term impact of the policy on behavior. This survey, identical across periods, collected information on the consumption of plastic bags, plus personal attitudes towards plastic bag use and its regulation. To ensure the availability of bag consumption data both before and after the policy was introduced, the survey used a standard recall question: consumers were asked to report the number of carrier bags they used or acquired on their last grocery shopping trip. $^{24,25}$ (Browning et al., 2003)

The survey was implemented by an established online market research company ${ }^{26}$, whose UK panel contains over 350,000 respondents varying widely by age, gender, education, and income. To obtain nationally representative samples, the survey used a quota-sampling strategy that set quotas for age, gender, and regional distribution of the population to match UK characteristics in each wave. Statistical analysis (median tests) demonstrates that respondents in the three waves do not differ significantly from one another, in terms of income $(\mathrm{p}=0.474)$, or education $(\mathrm{p}=0.716)$, indicating that the sample selection strategy operated in accordance with the design. The survey data also show that consumers moved across stores, with individuals visiting an average of 4 different retailer brands over a four-week period preceding the interview. This distribution and the sampling strategy set out before indicates that the sample can be expected to be reasonably representative of UK consumers, and that it remains relatively stable across the survey period. ${ }^{27,28}$

\footnotetext{
${ }^{24}$ Prior to the introduction of the charge, plastic bags were not individually charged and they were not scanned at the till (they had no bar code) nor recorded by the cashier, so there was little record of their consumption at the retail level. But see the discussion of pre-survey data in footnote 22 .

${ }^{25}$ Self-reported measures of behaviour are known to carry a downward bias (Schwarz, 1999, Browning et al., 2003), particularly when consumption is considered socially undesirable (e.g. alcohol in Feunekes et al., 1999). Consumption from recall can be accurate if the questionnaire is designed correctly: recalling a specific event, which has occurred recently, and having no time restriction to answer the question has been shown to give more precise measures of behaviour (Schwarz and Oyserman, 2001). As a result, respondents were asked to base their recall on their last grocery shopping trip and were given a scale to facilitate the task. The same recall approach was used to generate behavioural data.

${ }^{26}$ ResearchNow (www.researchnow.org.uk)

${ }^{27}$ We recognize that the choice of control group is crucial to obtain unbiased estimates using a difference-indifference estimator (as we do here), due to unobservable preferences for the environment varying across groups. Specifically, if the control group includes a disproportionate number of individuals who hold strong preferences for the environment before the legislative change is introduced, this could result in the failure to reject a false null hypothesis (a type II error) by showing little change after the policy is introduced. Similarly, the incorrect inclusion of individuals who are initially unexposed to the charge in the control group would result
} 
The survey was short and straightforward. (See Survey in the Online Appendix A.) It consisted of twenty-one questions. Five of these concerned individual demographics (income, household, etc). Five others concerned recent plastic bag consumption. Seven concerned the individual's attitude toward the use of plastic bags, and toward the legal change. Four final questions concerned the broader context of individual choice regarding plastic bag consumption (substitutes for bags etc). All participants completed the survey in 5 minutes or less.

The idea of our experiment is to use the legal change regarding plastic bags to assess both how bag usage and how consumer attitudes were changing over the first two months of the new regime; in doing so, we then wish to separate out between those effects of the law caused by inculcation of values and those caused by the law itself (including the penalty). In order to accomplish this objective, each survey collected information on preferences/attitudes (on scales from zero to 100). Specifically, we focus on a measure for internalization or intrinsic motivation, measured by an attitudinal question included in the survey assessing the individual respondent's level of agreement with the statement "Minimizing the number of plastic carrier bags when I shop for groceries is important to me, regardless of any benefit or inconvenience that may result to me." We consider that this attitudinal indicator captures the internalized motivational effect from compliance with the objectives of the law. The idea being that there exists a distinct flow of benefits to the respondent from that individual's observance of the law, irrespective of any other benefits/costs that may flow from the chosen behavior. ${ }^{29}$

The impact of the plastic bag charge initially is identified using a differences-in-differences (DID) estimator across treatment and control jurisdictions. In fact, this type of estimator requires variability in the sample along two dimensions: firstly, the sample should contain information of

in a significant change in consumption in response to the legislative change, favouring the incorrect rejection of a true null hypothesis (a type I error). The sampling method must attempt to randomize adequately to avoid such in-built biases across treatments and controls.

${ }^{28}$ Note that we have tested for robustness, in regard to our selection of treatment and controls, by repeating our exercise, with little difference in results. See Online Appendix B for a description of our robustness checks and results.

${ }^{29}$ We posit that this indicator captures reported internalized individual motivation to avoid plastic bag consumption, motivated by the desire to conform to the new law and/or to adopt the law as a personal objective (i.e. to reduce the use of plastic bags) or via one of the other channels listed discussed above. 
behavior before and after the policy is introduced; secondly, in both periods the sample should include a number of individuals who are not affected by the policy when implemented, which represent a control group against which changes are compared (Bertrand et al., 2004). The market in the UK presented institutional differences enabling just such a quasi-experimental design: Wales introduced a plastic bag charge on the $1^{\text {st }}$ of October 2011, followed by Northern Ireland on the $1^{\text {st }}$ of April 2013, and by Scotland on the $20^{\text {th }}$ of October 2014. Since these are neighboring jurisdictions to the subject population, and our survey was conducted before and after the introduction of the law, a differencesin-differences analysis is appropriate in this setting.

In sum, the dataset from our survey contains the essence of a quasi-experiment. The plastic bags charge legislation impacted only English consumers (the "treatment group"). The remainder of the sample is from neighboring jurisdictions without the new (English) charge - subjects in the Northern Irish, Scottish and Welsh jurisdictions (the "control group"). ${ }^{30}$ The survey was implemented over eight weeks - one week before the legal change, one week after, and then seven weeks after the change. This sort of variation across two dimensions is what is required in order to undertake a reasonably controlled experimental analysis of the causes behind changes in individual motivation. In the next section we examine the results from this experiment.

\section{Results: Estimating Behavioral Change and Internalization}

The results reported here concern the manner in which the legal change impacted behavior (4.1), the evidence for the internalization of law (4.2), and the separation of the aggregate behavioral change into components attributable to intrinsic motivation and to the price-based effect of the new sanctions (4.3).

\subsection{General Impact of the Legal Change}

\footnotetext{
${ }^{30}$ Those in the control group were already subject to a charge, both in terms of an existing price per bag and their own distinct legal provisions. In most instances, the control group are un-treated rather than previously treated subjects in regard to the policy change. In order to investigate whether this distinction makes a difference in this context, we do various robustness checks in Online Appendix B.
} 
A first question related to the introduction of the charge concerns the measurable impact of this legal intervention, measured in terms of plastic bag consumption (new and re-used) in the treated jurisdiction (England). Table 1 shows that on average total plastic bag use in England (the treatment group) decreased slightly overall in the weeks following the introduction of the charge, going from 4.58 to 4.20 units per person. On the other hand, average consumption of new plastic bags fell about $45 \%$, from around 2.80 units per person per trip to just over 1.45 bags. This is an important difference, in that the law applies only to new plastic bags, and to the reduction in their use.

Table 1: Mean behavioral and attitudinal variables in the sample

\begin{tabular}{|c|c|c|c|c|c|}
\hline & Variable & Survey 1 & Survey 2 & Survey 3 & $\begin{array}{c}\text { Kruskal } \\
\text { Wallis - chi2 }\end{array}$ \\
\hline \multirow[t]{5}{*}{ Control } & Bag used - All & 3.99 & 3.86 & 4.10 & 0.09 \\
\hline & Bag used-New & 1.26 & 1.56 & 1.40 & 1.36 \\
\hline & $\begin{array}{l}\text { Reusable bag - } \\
\text { carried }\end{array}$ & 1.22 & 1.26 & 1.24 & 0.57 \\
\hline & $\begin{array}{l}\text { Reusable bag - } \\
\text { purchased }\end{array}$ & 1.79 & 1.66 & 1.73 & 5.99 \\
\hline & Intrinsic motivation & 71.49 & 69.97 & 68.37 & 0.42 \\
\hline \multirow[t]{6}{*}{ Treated } & Bag used - All & 4.58 & 4.47 & 4.20 & 4.72 \\
\hline & Bag used-New & 2.80 & 1.97 & 1.45 & $113.90 * *$ \\
\hline & $\begin{array}{l}\text { Reusable bag - } \\
\text { carried }\end{array}$ & 1.41 & 1.29 & 1.25 & $45.19 * *$ \\
\hline & $\begin{array}{l}\text { Reusable bag - } \\
\text { purchased }\end{array}$ & 1.76 & 1.69 & 1.72 & $8.90 *$ \\
\hline & Intrinsic motivation & 63.44 & 66.30 & 64.75 & 3.75 \\
\hline & Observations & 900 & 900 & 904 & \\
\hline
\end{tabular}

Significance levels are denoted as follows: $* \mathrm{p}<.05 ; * * \mathrm{p}<.01$

Table 1 also summarizes the individually reported changes in intrinsic motivation toward the use of plastic bags. These show significantly different trends for treatment and control groups. Specifically, respondents in the control group reported a slight and steady but insignificant $(\mathrm{p}=0.81)$ decline in intrinsic motivation over time; while respondents in the treatment group show an overall increase over the course of the experiment (of marginal significance, i.e. $\mathrm{p}=0.15$ ), but with an initially large and significant increase in intrinsic motivation $(\mathrm{p}=0.05)$. So, an interesting impact is occurring in the treatment group, primarily at the time of the law's initial adoption, and tapering off thereafter. 
It is important to note that these univariate tests only demonstrate the general nature of changes occurring across time, but the actual impact of the policy should be measured as the difference in this change across the two groups, to which we turn now. Figure 1 shows the distribution of the consumption of both new and all plastic bags in the three survey periods in the differing jurisdictions. ${ }^{31}$ The consumption of new plastic bags has declined much more rapidly in the treatment group, dropping from 2.80 to 1.45 while the control group's consumption from the sample increased slightly from an average of 1.26 to 1.40 new bags. The impact of the new law is clearly observable in the way that the treated jurisdiction responds regarding the use of new bags, relative to the behavior observable in the control jurisdictions. ${ }^{32}$

Figure 1: Impact of Law on Behavior over Time - Control and Treatment Jurisdictions

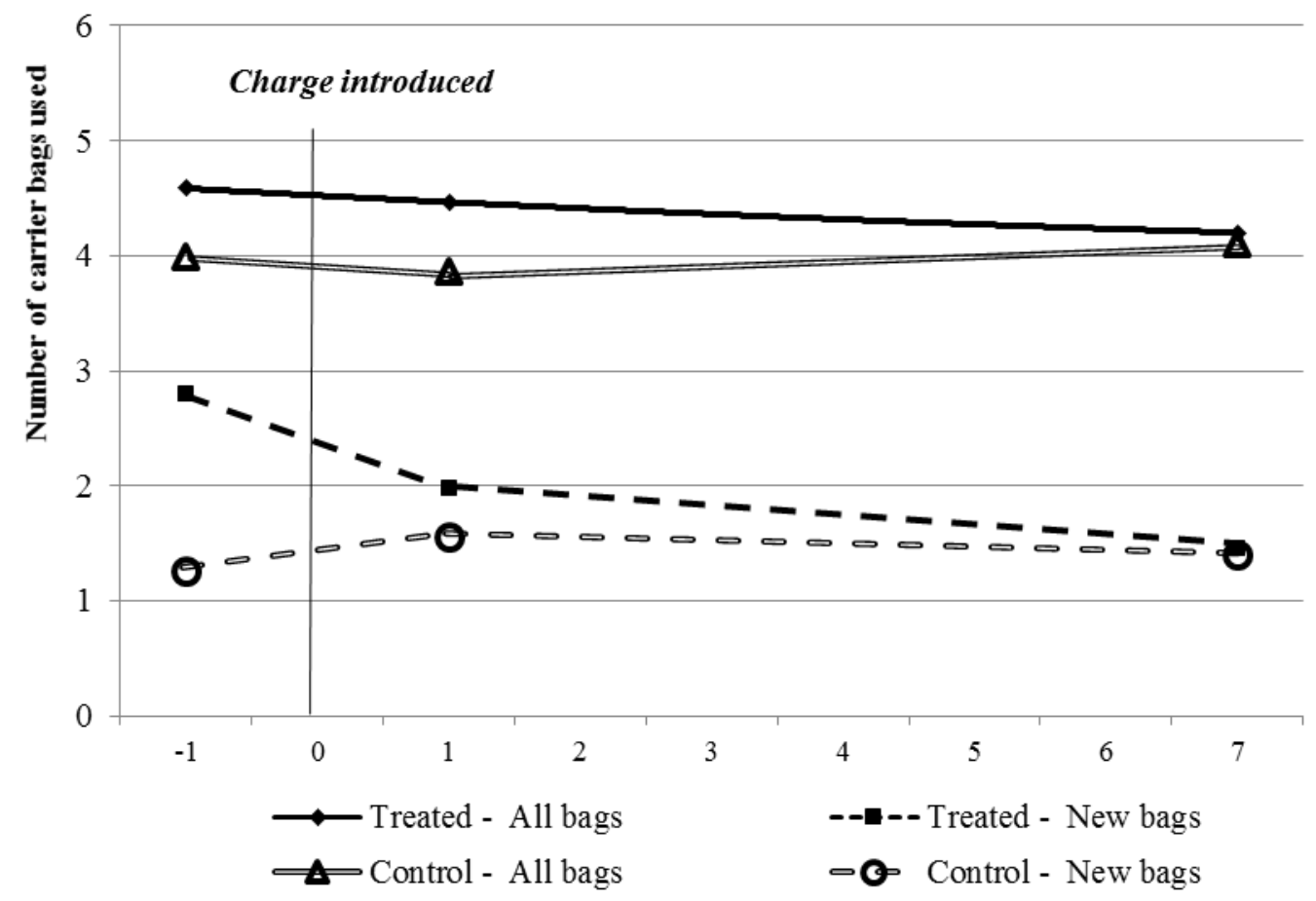

\footnotetext{
${ }^{31}$ A Kolmogorov-Smirnov test indicates that the distribution of total plastic bags used in the sample did not change significantly over time, while the distribution of new bags shifted toward zero. Figure 1 shows that individuals previously unexposed to the mandatory charge showed both a decline in total as well as new plastic bags (p-values for trend equal to 0.022 and 0.000 , respectively).

32 The intervention had little impact on the overall use of plastic bags. Oddly, there is a significant effect on the uptake of all plastic bags ( $\mathrm{p}$-value for trend $=0.000$ ) in the control group (i.e. consumers previously paying for their use), but not for the treatment group ( $\mathrm{p}$-value for trend $=0.916$ ). Overall, the trends are fairly flat. This is to be expected since the law addressed only the use of "new bags".
} 


\subsection{Testing for the Existence of Internalization of Law}

We turn now to the seminal question addressed in this paper: the existence of a discernible impact of the internalization of law. We can see this immediately, looking at the impact of the legal change across jurisdictions, both treatment and controls, in terms of the change in reported intrinsic motivation.

Figure 2 presents the trends in intrinsic motivation for control and treatments separately, confirming the patterns and significances discussed in the previous section. Internalized motivations jumped sharply in the treatment group immediately upon introduction of the law. This is compared to a general downward trend in motivation amongst the control group. After this initial jump in internalized motivations among the treatment group, intrinsic motivation then moves in line with the general trend of the control. 


\section{Figure 2: Impact of Law on Intrinsic Motivation over Time - Control and Treatments}

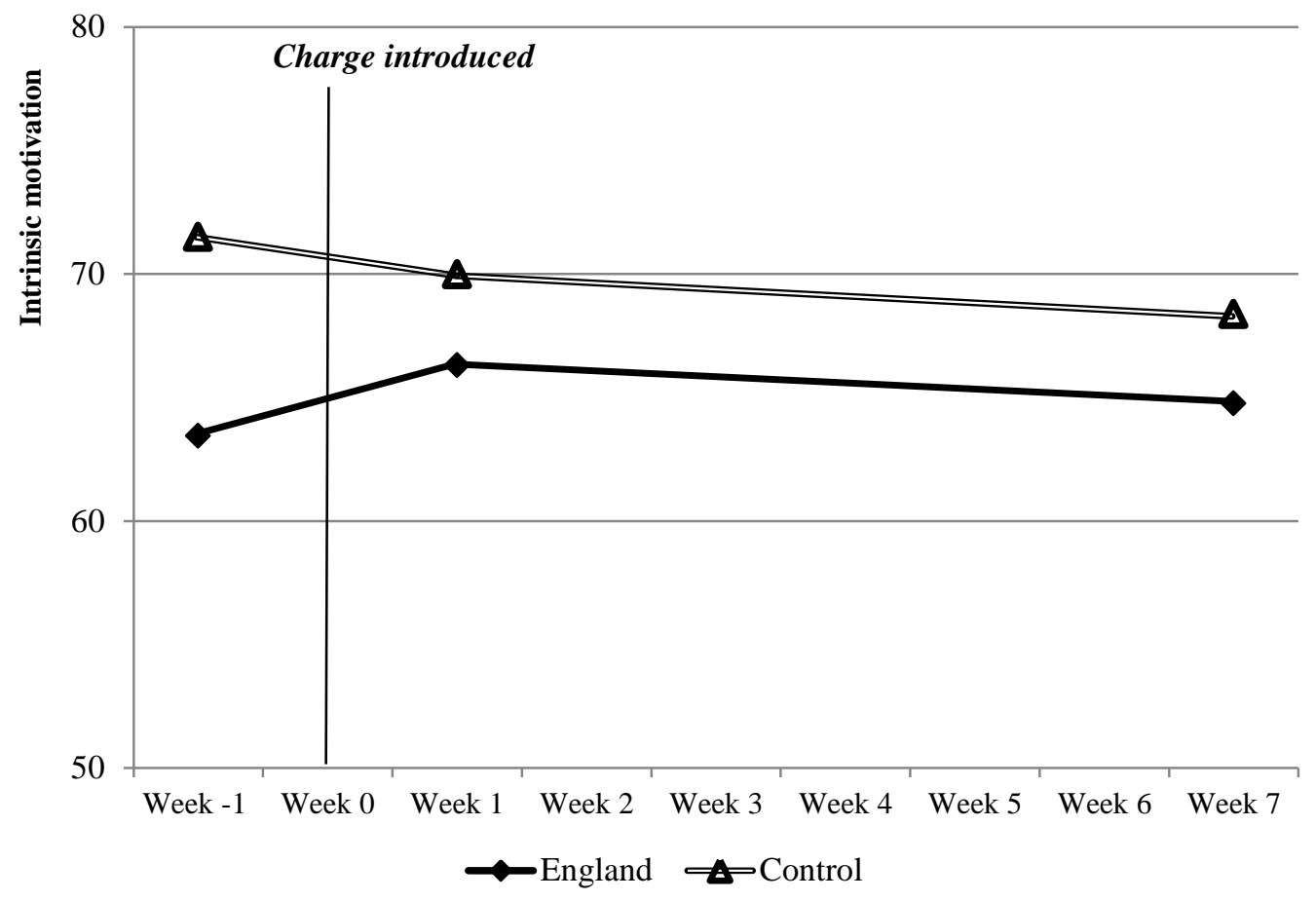

Interestingly, a sort of alignment between treatment and controls is observable in terms of both motivation and in actual consumption over the course of the experiment. That is, the overall effect of the intervention seems to be bringing the two groups (control and treatment) into alignment regarding the regulated behavior - both jurisdictions arriving at the use of an average of about 1.4 new bags per week (and 4 bags overall per week), from very different starting points. Likewise, reported levels of intrinsic motivation increased in England and declined in the other jurisdictions, converging somewhere in the upper 60s (out of 100).

In order to ascertain whether these differences between groups are indeed significant, we undertake a formalized difference-in-difference (DID) analysis. In doing so, we define plastic bag consumption of individual $i$ in group $s$ (control, treatment) at time $t$ as $Y_{i s t}$. The total impact of the policy on the target consumers can then be written as the difference in consumption between those individuals previously unexposed to the charge compared to the difference in consumption for the group of those individuals who were exposed to the charge at an earlier point in time (Imbens and Wooldridge, 2009), as follows: 


$$
\beta=\left[Y_{i}(s=1, t=1)-Y_{i}(s=1, t=0)\right]-\left[Y_{i}(s=0, t=1)-Y_{i}(s=0, t=0)\right]
$$

Equation (2) represents a difference-in-difference (DID) estimator of the impact of the legislative change, which is the difference between the change in plastic bags use observed in the treatment (England) $\left[Y_{i}(s=1, t=1)-Y_{i}(s=1, t=0)\right]$, and the change in plastic bags use measured in the control group $\left[Y_{i}(s=0, t=1)-Y_{i}(s=0, t=0)\right] .{ }^{33}$ This effect is estimated by the regression (Bertrand et al., 2004):

$$
Y_{i s t}=A_{s}+B_{t}+\beta I_{s t}+\gamma D_{i s t}+\varepsilon_{i s t}
$$

where $A$ refers to group-specific fixed effects, capturing systematic differences between control group and the initially unexposed group (e.g. different plastic bags needs); $B$ refers to time-specific fixed effects that capture the presence of the plastic bags charge if $t>0$; and $\varepsilon$ is the error term. In equation (3), I refers to the interaction term between the treatment dummy (equal to one for those initially unexposed to the charge) and the legislative change dummy. Then, $\beta$ captures the impact of the legislative change, measuring the change in consumption of people exposed to the plastic bag charge for the first time relative to the control group who were previously exposed to the charge. ${ }^{34}$

Table 2 presents the results of the difference-in-differences estimation. The results demonstrate that the change in law had a large and significant impact on the use of new plastic bags in the treatment jurisdiction (England). ${ }^{35}$ Compared to the control group (and including the effect of internalized motivation), it can be seen that new plastic bag use fell by around 1.8 bags one week after the charge was introduced and by 2.5 bags seven weeks after. ${ }^{36}$ It is also noteworthy that both coefficients are significant at the 1 per cent level. As would be expected, the impact on total plastic bags use is much more modest, with a decline of around 0.5 bags per person per trip in the last round

\footnotetext{
${ }^{33}$ In this representation, $\mathrm{s}$ refers to the jurisdiction under examination ( $\mathrm{s}=1$ is treatment; $\mathrm{s}=0$ is control) and $\mathrm{t}$ refers to the treatment ( $\mathrm{t}=1$ is exposure to the treatment; $\mathrm{t}=0$ is non-exposure).

${ }^{34}$ Importantly, the presence of different time periods causes a problem of serial autocorrelation of the residuals $\varepsilon_{\text {ist }}$ (Bertrand et al., 2004); this problem can be significantly mitigated by clustering residuals by period (Wooldridge, 2003).

${ }^{35}$ The complete table with controls and diagnostics is available in the Online Appendix as Table OA2.

${ }^{36}$ As expected, the impact on overall use of plastic bags is smaller relative to that of new plastic bags, since it is the use of the latter that is actually regulated.
} 
of surveys. In line with the intended purpose of the legal change, this suggests that consumers are recycling their plastic carrier bags, rather than vastly minimizing their use per se.

The change in regulatory framework also has an impact on intrinsic motivation: first, intrinsic motivation increases by 3.67 points the week after the introduction of the charge (listed under England*Wave 2), halving the 7.61 difference in (reduced) motivation that formerly characterized English consumers; second, this increase in motivation remains almost unchanged after 7 weeks (at 3.41 - and listed under England*Wave3). It is noteworthy that these coefficients are also significant at the 1 per cent level.

Table 2: Impact of the charge on use of plastic bags - with and without internalization

\begin{tabular}{c|cc|cc|c}
\hline & All bags & & New bags & Intrinsic \\
motivations
\end{tabular}

Significance levels are denoted as follows: $* \mathrm{p}<.05 ; * * \mathrm{p}<.01$. Treated Group refers to respondents within jurisdictions of legal change. Period i refers to respondents to ith survey. Policy, time i refers to respondents within treated group in period $\mathrm{i}$.

Is there a discernible impact of intrinsic motivation on behavior? While intrinsic motivation has no impact on the total consumption of plastic bags (which would be driven by other factors, such as household size, or purpose of the shopping trip), motivation has a modest but significant impact on the rate of use of new plastic bags. This may be seen in Table 2 by comparing the columns labelled 
"with internalization" and "without", as an increase in intrinsic motivation is seen in the former column to result in a reduction of 0.0388 new bags consumed per unit of self-reported increased motivation. So, the difference-in-differences analysis demonstrates that reported increases in internal motivation - occurring in the jurisdiction with the change in law - are directly inducing changes in behavior regarding the use of new plastic bags. ${ }^{37}$

\subsection{Mediation Analysis: Measuring the Internalization of Law}

We have seen that the legal change impacted behavior regarding the regulated activity (reduction in new plastic bags), and that this may be linked to reported changes in intrinsic motivation. This evidence generally supports the belief in the internalization of law. Now we would like to explore the relative amount of the observed change in behavior that may be attributed to the increase in intrinsic motivation, occurring at the time of the expressed principle of legal change.

We do this by considering the impact of the introduction of the carrier bag charge on reported intrinsic motivations, as reported by our survey respondents. The fifth column of Table 2 presents the estimates of the impact of the plastic bag charge on intrinsic motivations using the difference-indifference estimator of equation (3). There are numerous interesting observations to be made about how attitudes are shifting. First, intrinsic motivations are increasing only in the treated jurisdictions; however, the data sees a slight decline in intrinsic motivation in wave 3 that is affecting all respondents. Nevertheless, the difference in the change in motivation across the two groups is significant in both survey periods, and remains reasonably stable over time. Importantly, while intrinsic motivations have a statistically weak impact on the overall consumption of plastic bags, as expected they are a strong driver of the decision to consume fewer new plastic bags.

These results indicate that the intervention has two effects: this change in law has resulted in differences across jurisdictions (treatment and control) both in regard to changes in behavior (the amount of the regulated activity) and changes in attitudes (self-reported intrinsic motivation to adopt

\footnotetext{
${ }^{37}$ As will be detailed in the discussion concerning DID below (fns. 39-40), this form of analysis is quasiexperimental in nature and designed to afford evidence of a causal relationship, so it is accurate here to speak of increased internal motivation causing a reduction in the use of new plastic bags.
} 
the legal change). To ascertain the contribution of changed attitudes to changed behaviors, we use mediation analysis (e.g. Baron and Kenny, 1986, MacKinnon et al., 2007). Results in table 2 indicate that this approach is appropriate: as expected, the introduction of intrinsic motivation to the DID regression (i.e. the "with internalization" results) reduces the magnitude of the coefficients estimating the impact of the legal change, an indication that part of the total effect of the policy is actually driven by changes in the attitudinal structure or motivation of the individual shopper.

A mediating factor is one that stands between the independent and dependent variable, and acts as a conduit for transmission of the effects of one on to the other. By allowing for the existence of a mediator, the approach attempts to quantify the contribution given by the change in that mediator (here, intrinsic motivation), and the contribution given by other more direct factors. Figure 3 graphically represents these two effects (termed direct and indirect), as defined by the mediation analysis and with reference to the coefficients estimated using the equations below. In practice, this approach tests the relative contribution of a so-called the mediator variable on a given dependent variable (here, the role of intrinsic motivation in affecting new plastic bag usage). That is, the mediator is a conduit that transmits in part the impact of a given stimulus (here, the change in law) upon a dependent variable (plastic bags consumption), and mediation analysis is the method by which the relative contributions of the mediator and other more direct factors are ascertained.

It is important to note that the mediation analysis is not sufficient in itself to identify causal effects, which can be obtained only if the underlying behavioral model is structurally identified (see, e.g., Keele, Tingley, and Yamamoto 2015; MacKinnon et al. 2007). ${ }^{38}$ We follow the existing literature in making the assumption that motivation drives behaviour, although the precise nature of this relationship remains a question for further research. ${ }^{39}$

\footnotetext{
${ }^{38}$ In our analysis, the link between motivation and behavior is not structurally defined: unobservable preferences may simultaneously determine the amount of intrinsic motivation and the number of bags purchased, a simultaneity that we do not address because of the nature of the residuals in OLS and Tobit; moreover, behaviour may influence motivation, resulting in reverse causality problems (e.g., Ariely and Norton 2008).

${ }^{39}$ If endogeneity is present in the manner discussed above (Ariely and Norton 2008), the estimated indirect effect might change depending on the bias on the coefficient - if behaviour increases motivation, the bias is upward; if doing good demotivates doing further good, there is a downward bias. We leave this point to future research, as we are not able to give more than a speculative answer to this very interesting question.
} 
(Fishbach, Eyal, and Finkelstein 2010) However, the key intuition underlying our approach here is that identification arises out of the method supplied by the precursor difference-indifferences (DID) analysis. DID design identifies the effect of the new law by eliding any other factors resulting in changes (in both motivation and plastic bag use) occasioned within the control group, leaving only the impact of the treatment to be observed within the treatment group (see, e.g., Imbens and Wooldridge 2009). ${ }^{40}$ With the above assumption regarding the nature of motivation effects and identification supplied by the DID analysis, the mediation analysis is then just a means by which to separate out the relative contribution of the regulatory change to observed impacts.

\footnotetext{
${ }^{40}$ As a quasi-experimental design, the difference-in-difference design identifies causal effects in any underlying behavioural model, as long as the group allocation is exogenous: in our case, causal identification of the policy change dummy holds as long as the decision to live in England is not related to plastic bags use and to the motivation to reduce plastic bags, after adjusting for all relevant covariates.
} 
Figure 3: Relationship between policy change and behavior

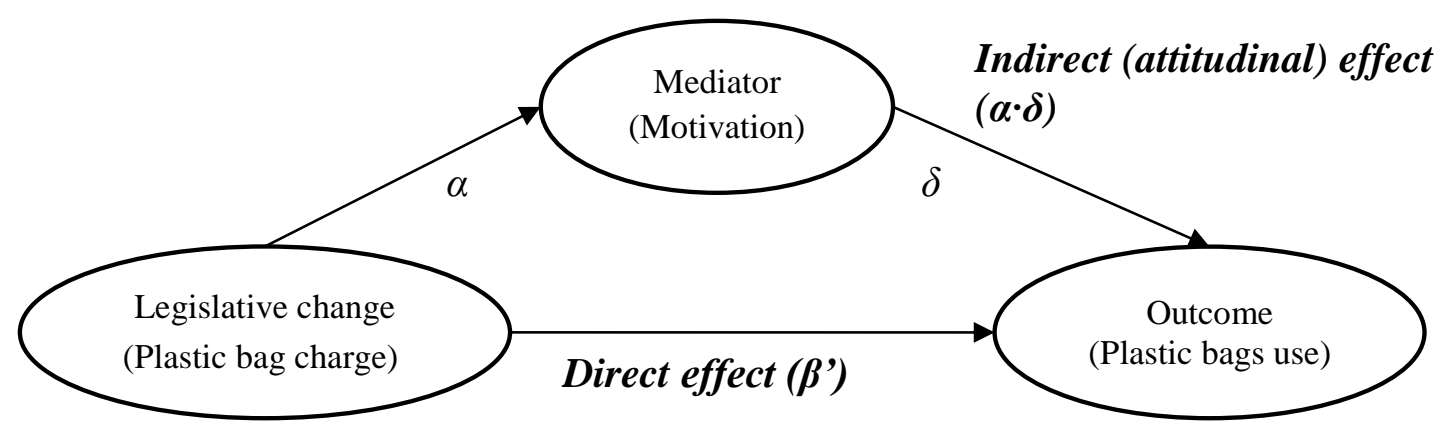

Adapted from Ludwig et al. (2011), page 19.

To perform the mediation analysis, behavior is modelled as a system of two equations. Firstly, consumption is modelled by extending equation (3) to adjust for the role of motivation $X$ on demand as

$$
Y_{i s t}=A_{s}^{\prime}+B_{t}^{\prime}+\beta^{\prime} I_{s t}+\delta X_{i s t}+\gamma^{\prime} D_{i s t}+\epsilon_{i s t}
$$

Similarly, internal motivation $X$ can be modelled as

$$
X_{i s t}=C_{s}+F_{t}+\alpha I_{s t}+\varphi D_{i s t}+u_{i s t}
$$

where $C$ and $F$ reflect group-specific and time-specific motivational fixed effects.

Figure 3 shows the direct effect and the indirect (attitudinal or motivation-based) effect obtained from the estimates of equations (4) and (5). The introduction of the plastic bag law and charge has a direct effect that reduces the use of plastic bags by $\beta$ ' units (equation (4)). The charge also has an indirect effect: the legislative change increases (decreases) the average internalized motivation in the sample by $\alpha$ units (equation (5)) and because each unit of motivation influences behavior by $\delta$ units (equation (4)), the charge will further reduce (increase) consumption by $\alpha \cdot \delta$ units.

Merging equations (4) and (5), we then obtain the aggregate equation

$$
Y_{i s t}=\left(A_{s}^{\prime}+\delta C_{s}\right)+\left(B_{t}^{\prime}+\delta F_{t}\right)+\left(\beta^{\prime}+\delta \alpha\right) I_{s t}+\left(\delta \varphi+\gamma^{\prime}\right) D_{i s t}+\left(\delta u_{i s t}+\epsilon_{i s t}\right)
$$




$$
\hat{\beta}=\left(\beta^{\prime}+\delta \alpha\right)
$$

which is the sum of a direct effect $\left(\beta^{\prime}\right)$ and an indirect effect $(\delta \alpha)$. The standard error of the indirect effect equals $\sigma_{\alpha \delta}=\sqrt{\sigma_{\alpha}^{2} \delta^{2}+\sigma_{\delta}^{2} \alpha^{2}}$ (Krull and McKinnon, 2001). ${ }^{41}$

The results of the mediation analysis are reported below in Table $3 .^{42}$ These estimates indicate that the reported motivational effect is a very small but significant contributor to the overall change in new plastic bag use. Specifically, one week after the charge was introduced, the impact of the law attributable to reported changes in motivations accounts for a reduction of around 0.07 new plastic bags per person per trip, against a non-attributed reduction of 0.91 new bags. Seven weeks after the policy was introduced, the attributed effect of the policy decreased very mildly in absolute value, causing a reduction of 0.06 new plastic bags per person per trip, against a non-attributed reduction of around 1.15 new bags. This means that the relative contribution of the change in intrinsic motivation represents about 5 to $8 \%$ of the total change in behavior.

Table 3: Mediation Analysis - direct and indirect effects of law on behavior

\begin{tabular}{l|c|ccc}
\hline & & New Bags & & \\
\hline & Period & Effect & S.E. & $\%$ \\
\hline Direct effect of policy & 1 & $-0.9099 * *$ & 0.0662 & $92.98 \%$ \\
& 2 & $-1.1522 * *$ & 0.0287 & $94.75 \%$ \\
\hline Indirect effect via & 1 & $-0.0687 * *$ & 0.0124 & $7.02 \%$ \\
Intrinsic motivation & 2 & $-0.0638 * *$ & 0.0115 & $5.25 \%$ \\
\hline Total effects & 1 & $-0.9786 * *$ & 0.0674 & \\
& 2 & $-1.2159 * *$ & 0.0309 & \\
\hline
\end{tabular}

Significance is as follows: $*=0.05 ; * *=0.01$.

\footnotetext{
${ }^{41}$ Notably, mediation analysis identifies causal effects only if two conditions hold (Keele et al., 2015). First, the charge has to be randomly assigned, i.e. the treatment variable $D$ in equation (4) has to be unrelated to unobservable preferences for plastic bags after adjusting for covariates. Secondly, attitudes must be exogenous to the behaviour given the remaining covariates, i.e. the main relation is structural. These points are discussed in more detail in Appendix B of the Online Appendix, when some robustness checks test whether these two conditions hold.

${ }^{42}$ Note that in the mediation analysis the policy coefficients from the Tobit equation are entered as the marginal effects of the censored value, rather than the coefficients of table 2, following the correction indicated by Puhani (2012); this adjustment is required to obtain a statistically consistent estimate of the DID when marginal effects are non-linear in the dependent variable.
} 
The results from our mediation analysis demonstrate that there is a clear internalization effect of law-making in this instance, as measured by the self-reported changes in attitudes of those individuals subjected to the new law. Although only able to explain about 5-8\% of the overall change in behavior, the associated change is clear and significant. We are able to conclude that, in this case, law has a measurable own-effect due to reported intrinsic motivation, and it appears to be reasonably stable over time. ${ }^{43}$

\section{Discussion}

This study sheds light on whether the internalization of law "exists". Many commentators cited the legal change related to the introduction of a plastic bag charge in Ireland as an example of the type that might register a significant impact via changed motivations. (Bowles and Polania-Reyes 2012). We have investigated the impact of a similar change in law in England in 2015 and we have been able to separate out between the direct price and indirect motivational effects. We found that indeed the change in law has fundamentally changed the way a significant proportion of consumers report their own levels of intrinsic motivation in response to the new law.

Another important enquiry concerns the relative contribution of changed motivations relative to other factors driving behavioral modification. Our main result in this regard derives from our mediation analysis which finds that the change in behavior attributable to changed values commences initially at about $8 \%$ of the total behavior change, and then ends at about $5 \%$ after almost two months of the law being in effect. This is a relatively small part of the impact of the charge, and highlights the importance of the direct price effect. It must be remembered, however, that while 5 pence is a small amount of money, it is considerably more than the production cost of a single use plastic bag (and probably about 5 times higher). ${ }^{44}$ In the context of goods with high price elasticity and substantial percentage

\footnotetext{
${ }^{43}$ Law has a measurable "own-effect" here, defined as an effect purely associated with the reported change in intrinsic motivations.

${ }^{44}$ Based on cost and compliance data supplied to the Department for Environment, Food and Rural Affairs (2017) by supermarkets, the average cost of a single use plastic bag to supermarkets is approximately 1 penny. Other (older) estimates have also placed the cost at approximately the same level (Conway 2007). Assuming competitive grocery retailing, and before a legal charge was introduced, the average shopper should have been expecting to pay about the production cost for each bag, i.e. about 1 pence.
} 
increases in the price, it seems reasonable to expect large behavioral changes to be brought about by direct price effects. ${ }^{45,46}$

While being relatively small in magnitude, we nevertheless find that there is clear-cut, significant evidence of the existence of internalized motivations to act in conformance with the law's objectives. This finding is important as it is an early example of the measurement of the actual internalization of law, as opposed to its inferral from observed behavioral change.

There are other interesting aspects of the English plastic bag charge case study. It is noteworthy in this case, that many of the factors that are often associated with the successful change of internal attitudes were present in the adoption of this law, including a high degree of perceived legitimacy regarding the legislative authority. (see Bilz and Nadler 2014) Importantly, the government also took a proactive role in expressing the reasoning behind the charge by publicly announcing it as a social responsibility, in particular highlighting the third party environmental costs associated with plastic bag use. These are important determinants in what makes for cost-effective law-making and implementation.

Finally, it is interesting that all jurisdictions are attaining the same equilibrium after the introduction of the law in terms of bag use, despite the fact that the new sanction was introduced in different jurisdictions at different points in time. This results in part from the fact that the charge in all jurisdictions (England, Wales, Scotland and Northern Ireland) was precisely the same (5 pence), and also from the observation that the price-based response to the charge was much of the reason for the reduction in bag consumption. ${ }^{47}$

\footnotetext{
${ }^{45}$ Assuming competitive grocery retailing, and before a legal charge was introduced, the average shopper should have been expecting to pay about the production cost for each bag, i.e. about 1 pence. With the introduction of the 5 pence charge, the 500 per cent increase in the price paid for a bag would be expected to induce a substantial response, assuming that there were ready substitutes available for new bags (such as reusable bags or previously acquired bags). In addition, given that many consumers may have seen the price of a new bag as zero, rather than the on-average 1 pence, the response might have been expected to be even more substantial. ${ }^{46}$ It is also noteworthy that for the much cited Irish plastic bag levy, the initial charge there was more than 10 times the production costs (Convery et al 2007, Conway 2007), demonstrating that price-effects were likely the reason for much of the behavioral change in that case as well.

${ }^{47}$ Given that the sanction was non-varying, and that many other unknown factors would be involved in the explanation of the phenomenon of convergence in bag consumption (e.g. local customs and attitudes, monitoring, perceived legitimacy of legislation, etc), we leave the question of convergence aside for future research.
} 
In drawing these conclusions we note that there are a number of limitations associated with our study, including the potential for self-reporting bias and the likelihood of different levels of attention and media coverage, pre-, post- and during the implementation of the charge. We also believe that there may be substantial grounds for further research in the general area of internalized motivations. One aspect that we have considered but not yet reached conclusions concerns the relative impact of legal change on various sub-groups (by age, by gender, by income), and how internalization varies with such characteristics. ${ }^{48}$ Another aspect of importance concerns the policy-relevance of internalization, and how governments and law-makers might be able to make it a more effective tool in cost-effective regulation. Many authors have written on this, and we have noted a few of the relevant factors present in regard to law-making in England in this case, but structured study of actual policy-making and implementation remains to be done. Nonetheless we consider this study to be an early advance in ascertaining the existence of internalized motivations, and measuring the extent to which the objectives of law are internalized through such motivations.

\section{Conclusion}

Why do laws have effect? Do we sit at red stoplights in the middle of the night on account of internalized motivations, or the threat of governmental sanctions?

It has been hypothesized that a new law can have both effects, sometimes expressing the common duties of a populace and other times providing prices for regulated behaviors. We have reported on an experiment to test this hypothesis in the context of the introduction of a plastic bag charge in England in 2015. In short, we find that the announcement of a bag charge in England did indeed have an immediate impact on behavior, changing the way in which agents used new bags in a very short

\footnotetext{
${ }^{48}$ Our initial results demonstrate that while the consumption of new plastic bags was significantly impacted by the age of the respondent (with response declining with age), the internalization of motives was not. These results are available from the authors on request.
} 
amount of time. Here we have used a policy-based quasi-experiment to demonstrate how the introduction of a new law resulted in immediate changes in behaviors regarding the regulated conduct.

In addition, we have attempted to measure the relative extent to which the behavioral change was attributable to the internalization of the law. We did this through a mediation analysis of stated changes in intrinsic motivation. We found the scale of the behavioral change attributed to intrinsic motivation was relatively minor but significant, contributing less than ten percent of the total impact in changed behavior over the two months of our survey.

We conclude that in this case the two systems (intrinsic and economic) work together within society's conception of law. Changes in law that incorporate economic incentives (such as fines, sanctions or charges) also may act - in part - as purely internalized law, altering the way that the populace views its own duties and obligations. Changes in behavior derive from both - the threat of sanctions and the internalization of motivations.

Overall, the internalization of law is an important tool in the effective implementation of law and regulation. We have noted that the English government undertook many of the actions that are hypothesized to be effective in generating high levels of intrinsic motivation, and it is in part a result of these actions that the plastic bag charge was taken on board by the people within that jurisdiction. It is certainly cost-effective to have the citizenry simply "follow the leader" in the adoption of socially-beneficial behavior patterns, and it will be interesting to pursue further precisely which parameters (policies, prices) determine the degree of own-effect of new laws. 


\section{References}

Apesteguia, Jose, Patricia Funk, and Nagore Iriberri. 2013. "Promoting rule compliance in daily-life: Evidence from a randomized field experiment in the public libraries of Barcelona." European Economic Review 64: 266-284.

Ariely, Dan and Michael I. Norton (2008), "How Actions Create - Not Just Reveal - Preferences," Trends in Cognitive Sciences, 12 (1), 13-16.

Athey, Susan and Guido W. Imbens (2006), "Identification and Inference in Nonlinear Difference-inDifferences Models," Econometrica, 74 (2), 431-97.

Baron, Reuben M., and David A. Kenny. 1986. "The moderator-mediator variable distinction in social psychological research: Conceptual, strategic, and statistical considerations." Journal of personality and social psychology 51(6): 1173-1182

Belkin, Douglas. 2003 "Boston firefighters sick-or tired of working." Boston Globe 18.

Bénabou, Roland \& Jean Tirole, 2006. "Incentives and Prosocial Behavior," American Economic Review, vol. 96(5), pages 1652-1678, December

Benabou, Roland, and Jean Tirole. 2011a. "Laws and norms." National Bureau of Economic Research Working Paper No. w17579.

Roland Bénabou and Jean Tirole, 2011b. "Identity, Morals, and Taboos: Beliefs as Assets" The Quarterly Journal of Economics (2011) 126 (2): 805-855

Besley, Timothy J., Gwyn Bevan, and Konrad Burchardi. 2009. "Naming \& Shaming: The impacts of different regimes on hospital waiting times in England and Wales." Mimeo.

Besley, Timothy J., and Maitreesh Ghatak. 2016. "Market Incentives and the Evolution of Intrinsic Motivation." Mimeo.

Berger, Melissa, Gerlinde Fellner-Röhling, Rupert Sausgruber, and Christian Traxler. 2016. "Higher taxes, more evasion? Evidence from border differentials in TV license fees." Journal of Public Economics 135: 74-86.

Bertrand, Marianne, Esther Duflo, and Sendhil Mullainathan. 2004. "How Much Should We Trust Differences-in-Differences Estimates?” The Quarterly Journal of Economics, 119, 249-275.

Bilz, K. and Nadler, J. 2014. Law, Moral Attitudes, and Behavioral Change. In: ZAMIR, E. \& TEICHMAN, D. (eds.) The Oxford Handbook of Behavioral Economics and the Law. Oxford: Oxford University Press.

Bowles, Samuel, and Sandra Polania-Reyes. 2012. "Economic Incentives and Social Preferences: Substitutes or Complements?" Journal of Economic Literature, 50, 368-425.

Browning, Martin, Thomas F. Crossley, and Guglielmo Weber. 2003. "Asking consumption questions in general purpose surveys". The Economic Journal, 113, F540-F567.

Conway, Chris. 2007. Taking Aim at All Those Plastic Bags. The New York Times. https://www.nytimes.com/2007/04/01/weekinreview/01basics.html 
Cooter, Robert D. 1998. "Expressive Law and Economics”. The Journal of Legal Studies, 27, 585607.

Convery, Frank, Simon McDonnell, and Susana Ferreira. 2007. "The most popular tax in Europe? Lessons from the Irish plastic bags levy." Environmental and Resource Economics 38(1): 1-11.

Dal Bó, Ernesto, and Pedro Dal Bó. 2014. Do the right thing: The effects of moral suasion on cooperation. Journal of Public Economics 117: 28-38.

Department for Environment, Food and Rural Affairs. 2017. Single-use plastic carrier bags charge data for England. Available: https://data.gov.uk/dataset/682843a8-168c-4056-b6fe741161a39f60/single-use-plastic-carrier-bags-charge-data-for-england. [Accessed June 2018]

Disney, Kate, Julian Le Grand, and Giles Atkinson. 2013. From irresponsible knaves to responsible knights for just 5p: behavioural public policy and the environment. In: Oliver, A. (ed.) Behavioural Public Policy. Cambridge: Cambridge University Press.

Dwenger, Nadja, Henrik Kleven, Imran Rasul, and Johannes Rincke. 2016. "Extrinsic and intrinsic motivations for tax compliance: Evidence from a field experiment in Germany." American Economic Journal: Economic Policy.

Etzioni, Amitai. 2000. "Social norms: Internalization, persuasion, and history." Law and Society Review: 157-178.

Fellner, Gerlinde, Rupert Sausgruber, and Christian Traxler. 2013. "Testing enforcement strategies in the field: Threat, moral appeal and social information." Journal of the European Economic Association 11(3): 634-660.

Feunekes, Gerda IJ, Pieter van't Veer, Wija A. van Staveren, and Frans J. Kok. 1999. Alcohol intake assessment: the sober facts. American Journal of Epidemiology 150(1): 105-112.

Fishbach, Ayelet, Eyeal, Tal, and Finkelstein, Stacey (2010). How positive and negative feedback motivate goal pursuit. Social and Personality Psychology Compass 4/8: 517-530.

Funk, Peter (2007) Is there an expressive function of law? An empirical analysis of voting laws with symbolic fines. American Law and Economics Review 9: 135-159.

Galbiati, Roberto and Vertova, Pietro, 2014. How laws affect behaviour: Obligations, incentives and cooperative behaviour. International Review of Law and Economics 38: 48-57.

Gneezy, Uri, and Aldo Rustichini. 2000. “A Fine is a Price.” The Journal of Legal Studies, 29, 1-17.

Gneezy, Uri, Stephan Meier, and Pedro Rey-Biel. 2011. "When and why incentives (don't) work to modify behavior." The Journal of Economic Perspectives 25(4): 191-209.

Greenberger, Scott S. 2003. "Sick day abuses focus of fire talks." Boston Globe 17.

Hart, H. L. A. 1997. The Concept of Law (Second Edition), Oxford, Oxford University Press.

Holmås, Tor Helge, Egil Kjerstad, Hilde Lurås, and Odd Rune Straume. 2010 "Does monetary punishment crowd out pro-social motivation? A natural experiment on hospital length of stay." Journal of Economic Behavior \& Organization 75(2): 261-267.

House of Commons. 2014. Plastic Bags. In: committee, H. O. C. E. A. (ed.). London. 
Imbens, Guido W., and Jeffrey M. Wooldridge. 2009. "Recent developments in the econometrics of program evaluation." Journal of economic literature 47(1): 5-86.

Kaplow, Louis, and Steven Shavell. 2007. "Moral rules, the moral sentiments, and behavior: toward a theory of an optimal moral system." Journal of Political Economy 115(3), 494-514.

Keele, Luke, Dustin Tingley, and Teppei Yamamoto. 2015. "Identifying mechanisms behind policy interventions via causal mediation analysis." Journal of Policy Analysis and Management 34(4): 937963.

Kleven, Henrik Jacobsen, Martin B. Knudsen, Claus Thustrup Kreiner, Søren Pedersen, and Emmanuel Saez. 2011. "Unwilling or unable to cheat? Evidence from a tax audit experiment in Denmark." Econometrica 79(3): 651-692.

Kreps, David M. "Intrinsic motivation and extrinsic incentives." 1997 The American Economic Review 87(2): 359-364.

Lin, Chung-cheng, and C. C. Yang. 2006. "Fine enough or don't fine at all." Journal of Economic Behavior \& Organization 59(2): 195-213.

Ludwig, Jens, Jeffrey R. Kling, and Sendhil Mullainathan. 2011. "Mechanism experiments and policy evaluations." The Journal of Economic Perspectives 25(3): 17-38.

MacKinnon, David P., Amanda J. Fairchild, and Matthew S. Fritz. 2007. "Mediation analysis." Annual review of psychology 58: 593-614.

McAdams, Richard H. 1997. "The origin, development, and regulation of norms." Michigan Law Review 96(2): 338-433.

Puhani, Patrick A. (2012), "The Treatment Effect, the Cross Difference, and the Interaction Term in Nonlinear "Difference-in-Differences" Models," Economics Letters, 115 (1), 85-87.

Poortinga, Wouter, Lorraine Whitmarsh, and Christine Suffolk. 2013. "The introduction of a singleuse carrier bag charge in Wales: Attitude change and behavioural spillover effects." Journal of Environmental Psychology 36, 240-247.

Romaniuc, Rustam, 2016. What makes law change behaviour? An experimental study, Review of Law and Economics, vol. 12, issue 2, 447-475.

Romaniuc, Rustam, Katherine Farrow, Lisette Ibanez, and Alain Marciano. 2016. "The perils of government enforcement." Public Choice 166(1-2): 161-182.

Schwarz, Norbert. 1999. "Self-reports: how the questions shape the answers." American psychologist 54(2): 93-105.

Schwarz, Norbert, and Daphna Oyserman. 2001 "Asking questions about behavior: Cognition, communication, and questionnaire construction." American Journal of Evaluation 22(2): 127-160.

Scott, Robert E. 2000. "The limits of behavioural theories of law and social norms", Virginia Law Review, 86(8): 1603-1647.

Shavell, Steven. 2012. "When Is Compliance with the Law Socially Desirable?." The Journal of Legal Studies 41(1): 1-36. 
Sunstein, Cass R. 1996. "On the expressive function of law." University of Pennsylvania Law Review 144(5): 2021-2053.

Titmuss, Richard. M. 1971. The gift relationship: from human blood to social policy, New York, Pantheon Books.

Tyran, Jean-Robert, and Feld, Lars, 2006. Achieving compliance when legal sanctions are nondeterrent, Scan. J. of Economics 108(1): 135-156.

UK Government. 2015. Carrier bags: why there's a charge. [Online]. London: Department for Environment Food and Rural Affairs. Available: https://www.gov.uk/government/publications/singleuse-plastic-carrier-bags-why-were-introducing-the-charge/carrier-bags-why-theres-a-5p-charge [Accessed 15 January 2016].

Wooldridge, Jeffrey M. 2003. "Cluster-sample methods in applied econometrics." The American Economic Review 93(2): 133-138.

WRAP. 2015. WRAP announces new carrier bag figures. [Online]. Available: http://www.wrap.org.uk/2015_carrier_bag_figures. [Accessed 15 January 2016].

Zhao, Xinshu, John G. Lynch, and Qimei Chen. 2010. "Reconsidering Baron and Kenny: Myths and truths about mediation analysis." Journal of consumer research 37(2): 197-206. 